\title{
Review of A Concise History of the
}

\section{Netherlands (1)}

\author{
BOB MOORE
}

Writing a history of this scope is a huge undertaking, involving the mastery of a bewildering array of literature that encompasses more than two millennia, and Professor Kennedy should be congratulated for his efforts in bringing the enterprise to a successful conclusion in his book A Concise History of the Netherlands. ${ }^{1}$ His decision to focus on the geographical entity that roughly corresponds to the political boundaries of the present-day Netherlands makes sense in an early twenty-first century context and differentiates his work from earlier scholarship that has tried to encompass the whole of the 'Low Countries', or the history of the Dutch-speaking peoples. That said, it could be argued that the premise behind the book is essentially teleological and that the writing concentrates on the features of history that have some relevance to the current political, social and economic structure of the Kingdom of the Netherlands as it is today. This is not necessarily a bad thing, as it brings to the foreground the question of who the audience for such a book might be? One suspects that it is primarily intended for the general reader interested in how the Netherlands came to be as it is, and in this regard, the narrative construction that interweaves the political with the social and economic works well to provide an understanding of the manifold processes involved.

Perhaps befitting a work on the Netherlands, there is a slight bias towards the economic in the text, but the author has managed to encapsulate many different features within a single period by seamlessly weaving them together. So successful is this, that the reader is often led into the next major discussion without realising that the subject matter has actually changed. This type of writing is a skill in its own right, and this seems to be a very good example of the genre. It is possible for the reader to dip in and out of the text, reading on a specific period, and be able to get the flavour of the history involved without feeling that it was essential to have read earlier 
sections. While the periodisation of the book, like everything else that it contains, is very much the choice of the author, he seems to have chosen wisely considering his terms of reference, and in his use of examples. Certainly, the book is an entertaining and engaging read and has within its covers something for everyone, general reader and specialist alike.

Starting from pre-Roman times, the seven chapters chart the development of what we now know as the Netherlands. There is an evenness of space given to each defined era, which means that the narrative is not swamped by the revolt of the sixteenth century and the golden age of the seventeenth that are so often used to define the nature of Holland, and by extension, the rest of the Netherlands as well. The author is careful to give due weight to the history of the other territories that formed part of the seven provinces although the attempt to summarise and explain the dynastic squabbles in the medieval period do sometimes come across as a bewildering parade of rulers, notables and locations. The maps provide some help for the reader in relation to the latter, although the detail incorporated might have been better served by colour rather than shaded illustration. In spite of this, the main themes considered central in this period are clearly elucidated, but often as conclusions to sections and chapters. It might have been more instructive to have these stated at the outset to give the reader a signpost to the arguments being presented, both in these early chapters and elsewhere.

The chapters that deal with the Netherlands' struggle for independence from Spanish control at the end of the sixteenth century and the golden age that followed, provide a clear synthesis of the narrative strands that are an essential part of the storytelling, as are the academic debates which have arisen to explain the ways in which the United Provinces emerged to be a major colonial and cultural power. This rise to prominence is given little more space than the slow decline in the eighteenth century as the country's fortunes waned. Here as elsewhere, the author incorporates not only a strong narrative strand, but illustrative examples that both inform and add colour to the pictures he is painting. As a non-specialist in this period, I found the treatment both interesting and informative, but trust I will be forgiven for moving the discussion to the parts of the book where the material is more familiar.

In his treatment of the twentieth century, the author's choices do manage to cover all the mainstream trends and features of the period. Although sometimes confined to a single line, the reader can be introduced to a whole debate. For example, the Dutch anger at the British treatment of the Boers in South Africa was a major political issue at the turn-of-thecentury but not one which could be allowed to undermine Anglo Dutch relations for any extended period. The section on the First World War neatly sums up the country's political predicament, as well as the economic and social consequences of neutrality. It shows in just a few pages how many 
of the trends evident in the belligerent states could also be found in the neutral Netherlands, not least in terms of economic deprivation and political radicalisation. In the immediate post-1918 period, the two international political crises faced by the Dutch government were the presence of Wilhelm II, the former German Kaiser on Dutch soil and the potential for a belligerent Belgium to make territorial gains at the expense of the neutral Netherlands in the peace settlement. The fact that both these issues were successfully overcome does not undermine their importance at the time, although in a survey work of this nature summary compromises are perhaps inevitable lest the whole text become completely unwieldy.

The analysis of the interwar period highlights the weakness of the Dutch economy when faced with the collapse in international trade and demonstrates how government policy probably lengthened the period of crisis by maintaining austerity measures longer than most other states in Europe. Here there is an implicit comparison with other states, a trend which is continued in the discussion of the rise of radical right-wing groups, in the case of the Netherlands most notably the NSB. While the use of comparison is also inherent in the historiography of the Holocaust, the discussion on the persecution of the Jews in the Netherlands during the Nazi occupation is confined almost exclusively to the Dutch case, with the only comparison being between the contrasting policies of the Amsterdam Jewish Council and its provincial counterpart in Enschede. Still one of the most contentious topics in recent Dutch history, the author navigates through the literature on the debates and manages to incorporate many of the key elements involved. In one or two places, the wording can be slightly misleading, for example in describing the rounding up of Jews in Amsterdam in February 1941 where 'they were transported to their deaths in Mauthausen' makes it seem that their deaths were the catalyst for the Februaristaking whereas in fact their fate was not known until several weeks afterwards. The victims in this tragedy are also reduced to little more than ciphers, symbolised only by the iconic, but nonetheless unrepresentative figure of Anne Frank.

The ways in which the narrative strand has been broken up in the text can also lead to some anomalies. For example, the claim that the country was 'one of the most materially devastated in Europe' probably needs some qualification but so does the figure for the number of deaths suffered by the Dutch population. Of the quarter million who lost their lives as a result of the conflict, more than 40 percent were the Jews deported to the death camps in Eastern Europe. Likewise the discussion of post-war immigration from the colonies, and the recruitment of gastarbeiders from Southern Europe, Turkey and Morocco also seem somewhat divorced from economic policies of the period. Economics and (post-) colonial policies were undoubtedly interrelated and given the importance of the debate on multiculturalism in the contemporary Netherlands, these issues might have been brought closer together.

The attempt to cover a myriad of political, social and economic factors in each era, as well as the many academic debates involved means 
that treatment of many elements is little more than cursory. This apparent eschewing of prioritisation does lead to some sections where one is left wondering whether the explanation can really be as simple as the text suggests. It would be very easy to criticise by saying that the author should have spent more time discussing this particular facet or that particular issue, but the truth of the matter is that this is essentially an introduction, a way for non-Dutch speaking students and general readers alike to find their way into the history of the Netherlands with the hope that their interest will be sufficiently aroused to consult the more detailed texts listed in the bibliography. This in itself betrays the fact that there is only a limited number of writings on many aspects of the history of the Netherlands that have actually appeared in the English language, something which is only now starting to be remedied.

The epilogue suggests that the author thinks the history of the Netherlands can be instructive, describing the Dutch as an 'adaptable people' who shaped a 'society conducive to human flourishing'. Whether that 'adaptation' was quite so much of a virtue between 1940- and 1945 is open to question, but there is no doubt that the pluralist model has served the country well in overcoming periods of revolution and riot. The wider issue of whether the Dutch provide a social and political model that others could and should espouse rather undermines the unstated assumption that 'the Dutch' are somehow special in their ability to construct a pluralist polity and a society that has managed to survive intact and largely undisturbed over many centuries. I suspect that the only test of these aspirations will be found in the country's history through the twenty-first century.

Bob Moore is Professor of Twentieth Century History, Department of History, University of Sheffield and currently Distinguished Fellow, Zentrum für Holocaust Studien, Institut für Zeitgeschichte, München. Email: r.moore@sheffield.ac.uk. 